\title{
Estudio de fraseología comparativa francés-español en la carta de Jean Louis Godin des Odonais a Charles-Marie de La Condamine
}

\section{Study of comparative phraseology French-Spanish in the letter of Jean Louis Godin des Odonais to Charles-Marie de La Condamine}

\author{
DOI: https://doi.org/10.29166/tyc.v1i21.2292
}

\section{Ekaterina Ignatova}

Estudió Filología en la Universidad Jaguelónica de Cracovia. Tiene una maestría en Filología y se especializó en la enseñanza de literatura y lengua rusa y francesa. Trabajó como catadrática en la Pontificia Universidad Católica del Ecuador (PUCE) por 30 años. Entre sus obras destacan Marco histórico de la literatura rusa del siglo XIX (1999); La desconocida y otros poemas de Aleksandr Blok (en colaboración con Iván Carvajal, 2009); Olas y otros poemas. Selección de poesía de Boris Pasternak (2015); En mi Moscú y otros poemas. Selección de poesía de Marina Tsvetáyeva (2017)

Correo: ignatova.ekaterina@gmail.com

\section{Resumen}

El presente estudio de fraseología comparativa se basa en la carta de Jean Louis Godin des Odonais dirigida a Charles-Marie de la Condamine y su traducción al idioma español. La carta narra el trágico viaje de Isabelle, esposa de Godin des Odonais, para reencontrarse con él después de más de 20 años de separación. El contenido de este emotivo documento explica la abundancia del material fraseológico del que nos servimos para formar, primero, el corpus del trabajo en ambas versiones y, posteriormente, presentar varias observaciones y reflexiones acerca de los procesos en francés y en español. En este estudio se expone la importancia del uso correcto de fraseologismos en las traducciones como también la necesidad de incluirlos desde el principio y en forma paulatina en el proceso de la enseñanza de los idiomas.

Palabras clave: lingüística, fraseología, traducción, historia, enseñanza, idiomas.

\section{Abstract}

The present study of comparative phraseology is based on the letter of Jean Louis Godin des Odonais addressed to Charles-Marie de la Condamine and its translation to the Spanish language. The letter narrates the tragic journey of Isabelle, Godin's wife, to reunite with him after more than 20 years of separation. The content of this emotional document explains the abundance of phraseological material that we use to form, first, the body of work in both versions and, later, to present various observations and reflections on the processes in French and in Spanish. In this study the importance of the correct use of phraseologies in translations is exposed as well as the need to include them from the beginning and gradually in the process of language teaching.

Keywords: linguistic, phraseology, translation, history, teaching, languages. 


\section{Contexto histórico}

"Llegaré, porque de la muerte estoy viva" se prometió aquél día viernes de la Semana Mayor de 1769 Isabel Grandmaison de Godin des Odonais. Aquella promesa, hecha por esta mujer riobambeña luego de haber superado los momentos más dramáticos de su épica travesía por la selva amazónica, no parecía tener ni la menor posibilidad de ser cumplida.

Fue la Providencia, tal como lo escribió más tarde Jean Louis Godin des Odonais, narrando la extraordinaria aventura de su esposa a Charles-Marie de La Condamine, o el premio a su valor casi inconsciente, lo que la hizo avanzar por la jungla amazónica, pero el hecho es que finalmente llegó a los brazos de su marido después de más de veinte años de separación.

El esposo de Isabel, Jean Louis Godin des Odonais, uno de los diez miembros de la Misión Geodésica francesa, llega al Ecuador en calidad de técnico y por ser sobrino de Louis Godin, el jefe de la expedición. Sin sentir ese fervor científico que dominaba el espíritu de su ilustre tío y de los otros dos miembros de la Academia -Pierre Bouguer y Charles-Marie de La Condamine-, Jean Louis Godin des Odonais dedicaba una buena parte de su tiempo a la vida social de Quito. Entre las familias de mayor abolengo, conoce a los Grandmaison, de origen francés, que le miran con buenos ojos, sobre todo su hija recién salida de un convento de Lima, la impulsiva y hermosa Isabel. Ella posee un atractivo inexplicable al cual no se puede resistir el joven Godin des Odonais. La boda se realiza en Quito y los festejos se prolongan en el campo por varios días.

En aquél tiempo, lleno de pasión y felicidad, era imposible prever o imaginar las huellas que dejó en la cara, el cuerpo y el alma de Isabel su posterior viaje hacia Cayena. Isabel parte de Riobamba el primero de octubre de 1769 , después de la muerte de su hija. Va acompañada de sus dos hermanos, quienes también viajan a Europa; del hijo de uno de ellos -todavía niño-, de un médico francés, de un esclavo negro, y de tres ayudantes domésticas.

Según cuenta Marc Blancpain en su libro Le plus long amour, "hace 20 años y siete meses, en marzo de 1749 , Jean Louis Godin des Odonais, el joven esposo francés, había emprendido el mismo camino."

Sería extenderse mucho en este trabajo narrar paso a paso las trágicas situaciones creadas tanto por la naturaleza humana como por la selvática. Sin embargo, antes de pasar directamente al tema de la actual investigación quiero compartir algunos hitos de ese viaje. En la última semana de diciembre de 1769 , en un claro de la jungla y a pocos pasos de una acequia, mueren de agotamiento y sed todos los acompañantes de Isabel (a excepción del médico francés y del esclavo negro que se habían adelantado para pedir ayuda). Isabel continúa su marcha, que

1 Marc Blancpain, Le plus long amour, Editorial Bernard Grasset, 1971, Paris, p.131. 
dura nueve días, al cabo de los cuales encuentra a dos indios a los que, en definitiva, debe la vida y a los que nunca olvidará. A partir de este momento, el viaje transcurre en condiciones relativamente favorables. Varios meses después, Isabel y Jean Louis se encuentran al fin.

El testimonio del mismo Jean Louis Godin, que alude a ese reencuentro, evoca “...Después de 20 años de separación (de hecho, más de 21 años), de noticias alarmantes, de travesías y de desgracias de ambos, me reencontré con mi querida esposa, a la que ya no tenía esperanza de volver a ver." 2

Isabel estaba enferma y exhausta por lo que Jean Louis esperó que se aliviara para poder "exponerla a un largo viaje por el mar. Abandonaron la casa a las orillas de Oyapock para dirigirse a Cayena y embarcar ahí el 21 de abril. El viaje no tuvo ningún inconveniente e Isabel, Jean Louis y Pierre (padre de Isabel), desembarcaron en La Rochelle después de 65 días de travesía el 26 de junio de 1773. Pasaron 38 años desde que Jean había abandonado Francia!"3

Pero aún viviendo en La Rochelle, en el seno de la familia de su esposo, hasta donde los Godin des Odonais llegaron el 26 de junio de 1773, su rostro nunca más se iluminaría con una sonrisa.

La carta que Godin des Odonais escribe a Charles-Marie de La Condamine en ese mismo año desde La Rochelle cumplirá en esta investigación sobre
Fraseología comparada la función de objeto de estudio y en ella analizaremos las unidades fraseológicas (UF) encontradas en este documento histórico, tanto en su versión original en francés como en su versión traducida al español . Pero antes, unas palabras sobre la ciencia de la Fraseología.

\section{Breve introducción a la Fraseología}

La Fraseología es una rama de la Lingüística que estudia el conjunto de modos de expresión de una lengua: frases hechas, locuciones, modismos, refranes, etc. El propósito de este trabajo es despertar el interés por el estudio de la Fraseología comparativa, de enorme utilidad en la traducción, imprescindible en la enseñanza de lenguas y en la comprensión e interpretación del texto. Es importante tener en cuenta que esta ciencia acude constantemente a varios aspectos de morfología, sintaxis, semántica, como también a psicolingüística y sociolingüística. Siendo fiel reflejo de las experiencias humanas, los fraseologismos o unidades fraseológicas (UF) nos guían por el camino de la psicolingüística: la dependencia mutua de la lengua y del pensamiento. El conocido lingüista francés Patrick Charaudeau escribe sobre el rol del lenguaje:

"Le langage est ce matériau qui permet à l'homme de construire du sens dans le monde tout en entrant en communica-

Blancpain, Op. Cit. p. 212

Blancpain, Op. Cit. p. 217

4 Carlos María La Condamine, "Viaje a la América Meridional”, [1745] Madrid, Espasa Calpe, 1942, Colección Austral, vol. 268. La obra Viaje a la América Meridional fue reeditada en 1778 e incluyó la carta que Louis Godin escribió a La Condamine el 28 de julio de 1773 sobre el penoso viaje de su esposa, Isabel. 
tion avec les autres. Le langage est à la fois, sens, expression et communication. Il n'est pas l'un et l'autre successivement, il est les trois à la fois." 5

Desde la perspectiva de la ciencia que nos interesa, la Fraseología cumple una función idéntica: es a la vez sentido, expresión y comunicación, no de manera sucesiva, sino de manera simultánea, es decir, es las tres cosas a la vez.

De ahí vemos que hay un solo paso para entrar en lo que Ferdinand de Saussure llamó "lingüistique externe" es decir, las relaciones entre la lengua y lo que está fuera de ella. Es tan amplia la gama de las ciencias involucradas que se podría mencionar solamente algunas de ellas como sociología, geografía, etnología, politología, etc. Saussure considera que "lingüistique externe" es de suma importancia en el momento de abordar el estudio de una lengua. Las UF desempeñan el papel doble: lingüístico y cultural. Si analizamos el primero vamos a ocuparnos de las leyes intrínsecas de cada idioma; con el segundo nos adentramos en el vasto paisaje compuesto de elementos históricos, folclóricos, costumbristas, sociales, religiosos, políticos y del arte.

Los hechos de la ciencia de la Fraseología son mucho más antiguos que su historia. ¿Por qué esa diferencia? Porque los hechos se presentan en forma tangible en los dichos, proverbios y locuciones cotidianas que sirven al ser humano para expresar su pensamiento y darle más "brillo". La existencia de estos hechos en cada lengua se extiende a lo largo de milenios.
Pero la ciencia que se ocupa de estas manifestaciones fraseológicas es mucho más joven. Todo lo que ella abarca constituye la "sal" y el "espíritu" de cada lengua en su máxima expresión.

En efecto, las locuciones de un idioma son la riqueza de una comunidad linguiística y se podrían comparar con un baúl lleno de monedas antiguas que, a pesar de tener un valor incalculable, no se pueden comercializar. El inventario de esta riqueza fraseológica es, al mismo tiempo, el testimonio del desarrollo sicológico de una nación. Cuidar de él e investigarlo no es solamente interesante, sino también muy necesario.

A veces los fraseologismos no se advierten $\mathrm{y}$, sin embargo, sintetizan toda una frase o pensamiento, por ejemplo: "sin más comentarios", "en efecto", "en resumidas cuentas". Así como los que podemos encontrar en todo contexto literario o en conversaciones cotidianas, por ejemplo "boca arriba", "a ojo cerrado", "en un dos por tres", "romper el corazón”, "a flor de piel".

En su Cours de Lingüistique générale, Ferdinand de Saussure hace referencia a las locutions toutes faites como elementos pertenecientes al sistema de la lengua. Saussure señala que existe toda una serie de frases que están hechas para la lengua. Su discípulo, Charles Bally, desarrolla el pensamiento de su profesor en tres estudios: Précis de Stylistique, Traité de stylistique française y Lingüistique générale et lingüistique française en los que se habla por primera vez de phraséologie para abarcar un conjunto de fenómenos

5 Patrick Charaudeau, Grammaire du sens et de l'expressión, Hachette Éducation, Paris, 1992, p.4. 
sintácticos y semánticos. Los trabajos de Bally tuvieron mucha influencia entre los lingüistas rusos (V. Vinogradov, A. Isačenko).

En el ámbito de la Fraseología española se pueden mencionar los nombres de Julio Caseres, Alberto Zuluaga, Gloria Corpas Pastor, Leonor Ruiz Gurillo y otros. Existe una considerable y multifacética pluralidad de las estructuras fraseológicas. La parcela de las estructuras comparativas de nuestro interés ofrece las posibilidades de descubrir analogías como también divergencias entre las comunidades idiomáticas.

En su estudio Unidades fraseológicas: un análisis contrastivo de los somatismos del español de Argentina $y$ del italiano, Virginia Sciutto apunta "los enunciados fraseológicos expresan la espontaneidad estilística de la forma de comunicar de una comunidad lin- güístico- cultural que los produce y los transmite de una generación a otra, desde los matices más sencillos y vulgares hasta sus aspectos filosóficos. Utilizados en el momento oportuno de una conversación pueden sustituir un largo discurso y tienen un gran valor expresivo"6.

Los fraseologismos adquieren mayor brillo y originalidad, sobre todo cuando los observamos y los comparamos con su equivalente en otro idioma. Los principios más generales de la formación de las locuciones producto de las operaciones mentales humanas son, en gran medida, universales y las diferencias son el resultado de las distintas estructuras de las lenguas y de las condiciones locales. A veces estas diferencias pueden encontrarse dentro de un mismo idioma, y en este caso son diferencias regionales como, por ejemplo:

Ejemplo:

\begin{tabular}{|l|l|}
\hline "Vender miel al colmenero." & Podría ser empleado en cualquier región. \\
\hline "Llevar piñas a Milagro." & Es estrictamente regional. \\
\hline "Wozić drzewa do lasu" (polaco) & \\
"Llevar la leña al bosque." & Podría ser empleado en cualquier región. \\
\hline $\begin{array}{l}\text { Exать в Tулу со своим самоваром (ruso) } \\
\text { "Viajar a la ciudad de Tula, con su propio samovar." }\end{array}$ & $\begin{array}{l}\text { Es estrictamente regional ya que Tula es una ciudad rusa, } \\
\text { conocida por su famosa industria de samovares. }\end{array}$ \\
\hline
\end{tabular}

6 Virginia Sciutto, Unidades fraseológicas: un análisis contrastivo de los somatismos del españól de Argentina y del italiano. Università di Napoli "L'Orientale' descargado de la red mundial el 13 de noviembre de 2011. http: cvc.cervantes.es/literatura/aispi/pdf/22/II_31.pdf 


\section{Tipos de unidades fraseológicas y ejemplos}

Se puede dividir la Fraseología de cada idioma en dos categorías básicas.

a) Fraseología natural y

b) Fraseología convencional

El desarrollo de la primera categoría está estrictamente unido con su "palabra-base" y todas las diferencias que se presentan son el resultado del entorno de esta base. Ese entorno, que podríamos llamar, "el material de empaque”, es muy variable. ¿En qué consiste este hecho? Se lo puede demostrar con los siguientes ejemplos:

Ejemplo:

\begin{tabular}{|l|l|}
\hline - Alzar el vuelo & • Cabeza de familia \\
\hline - Pájaro de alto vuelo & • Romperse la cabeza \\
\hline - Estar en pleno vuelo & - No tener pies ni cabeza \\
\hline
\end{tabular}

La Fraseología convencional, como se deduce de su nombre, es el producto de la creación artística de la humanidad. Cabe anotar que un elevadísimo porcentaje de la Fraseología convencional proviene de los textos de la Biblia, por ejemplo:

- No sólo de pan (vivirá el hombre). San Lucas 4.4

- Ver la brizna de paja en el ojo ajeno ( $\sin$ ver la viga de tu propio ojo). San Lucas 6.41

- Busca y hallarás. San Lucas 11.9

- Llevar su propia cruz. San Lucas 14.27
- No dejar piedra sobre piedra. San Lucas 19.44

- Aparta de mí esta copa. San Lucas 22.42

- Perdónalos porque no saben lo que hacen. San Lucas 23.34

\section{Acerca del corpus de esta investigación}

Las observaciones precedentes, igual que otras reflexiones, serán desarrolladas a partir del "corpus" de un texto escogido por las siguientes razones: su naturaleza doble relacionada con su apasionante contenido humano e histórico y su neutralidad lingüística. ¿A qué se debe esta aparente discordancia? Los hechos narrados en la carta de Louis Godin des Odonais hablan por sí solos: el drama de Isabel y sus acompañantes, lo que la marcó por el resto de sus días, los sufrimientos que nunca nadie pudo borrar de su memoria ni de su cuerpo, las condiciones del viaje que sobrepasan nuestra imaginación; y finalmente, la variedad de personajes que le ayudaron y los que quisieron hundirla mientras duró su odisea.

Es Godin des Odonais quien la narra, sin ser precisamente un hombre de letras, ni tener la pretensión de serlo. Su única preocupación era satisfacer el deseo de su exsuperior, Charles Marie de La Condamine, de saber de primera fuente la verdad de los acontecimientos. Godin des Odonais cumple con su tarea en los momentos en que La Condamine se encontraba en la cumbre de su popularidad, era una figura pública consentida incluso por el Papa Benedictino XIV. La posición de La Condamine le favorecía en forma plena para sus propósitos. 
A pesar de su estilo tan escueto que hasta deja la impresión de serlo premeditadamente en repetidas ocasiones, se produce una verdadera avalancha de locuciones. Tal parece que el texto lucha con el autor y en muchas páginas gana la batalla. Estos triunfos y fracasos de la Fraseología frente a la narrativa de Jean Louis Godin des Odonais, quien verbaliza sus sentimientos, es lo que constituyen el corpus de este trabajo.

El corpus se analizará desde las siguientes aproximaciones:

1. Su temática

2. La densidad de las locuciones

3. La correspondencia en ambos idiomas (el fenómeno de la "paridad")

4. El grado de libertad en su composición

5. Sus estructuras

Ello concuerda con la reflexión de Maribel Tercedor sobre la selección de un corpus de estudio: "Los estudios de la lengua deben basarse en el uso real, fiel y auténtico y no en frases inventadas y aisladas. El texto ha de ser representativo. La unidad de estudio debe ser el texto completo. Los textos y los diversos tipos de textos deben estudiarse comparativamente partiendo de córpora reales. El corpus debe ser relevante desde el punto de vista traductológico, a saber, que recoja la mayor muestra de variedades comunicativas. ${ }^{\text {" }}$

En el corpus de la investigación se encuentra gran cantidad de lo que Alberto Zuluaga llama las colocaciones, es decir, las construcciones lingüísticas a medio camino entre libres y fijas fraseológicamente. Los ejemplos que él propone, entre otros, son: "estado de ánimo", "ajuste de cuentas", "necesidad imperiosa", "gravemente herido", "correr el rumor", "correr el peligro", etc. En estos ejemplos, así como en los del presente trabajo se observa una estrecha relación entre ciertos verbos, nombres, adverbios, adjetivos.

Las colocaciones no presentan por lo general ninguna dificultad al ser analizadas: entre sus componentes casi siempre se encuentra un elemento metafórico ampliamente reconocido y aceptado por la comunidad lingüística. Dichas colocaciones o combinaciones recurrentes fueron destacadas ya por Bally y tratadas, entre otros, por A. Rothkegel.

Para confirmar los resultados de este trabajo, el inventario de UF analizará las expresiones tanto en el idioma original francés, como en la traducción al español.

7 Maribel Tercedor Sánchez, "La Fraseología en el lenguaje biomédico: análisis desde las necesidades del traductor", tesis doctoral, Departamento de Traducción e Interpretación, Universidad de Granada descargado de la red mundial el 23 de diciembre de 2011. http://148.216.10.84/freseologia/iii-metodo.htm. 


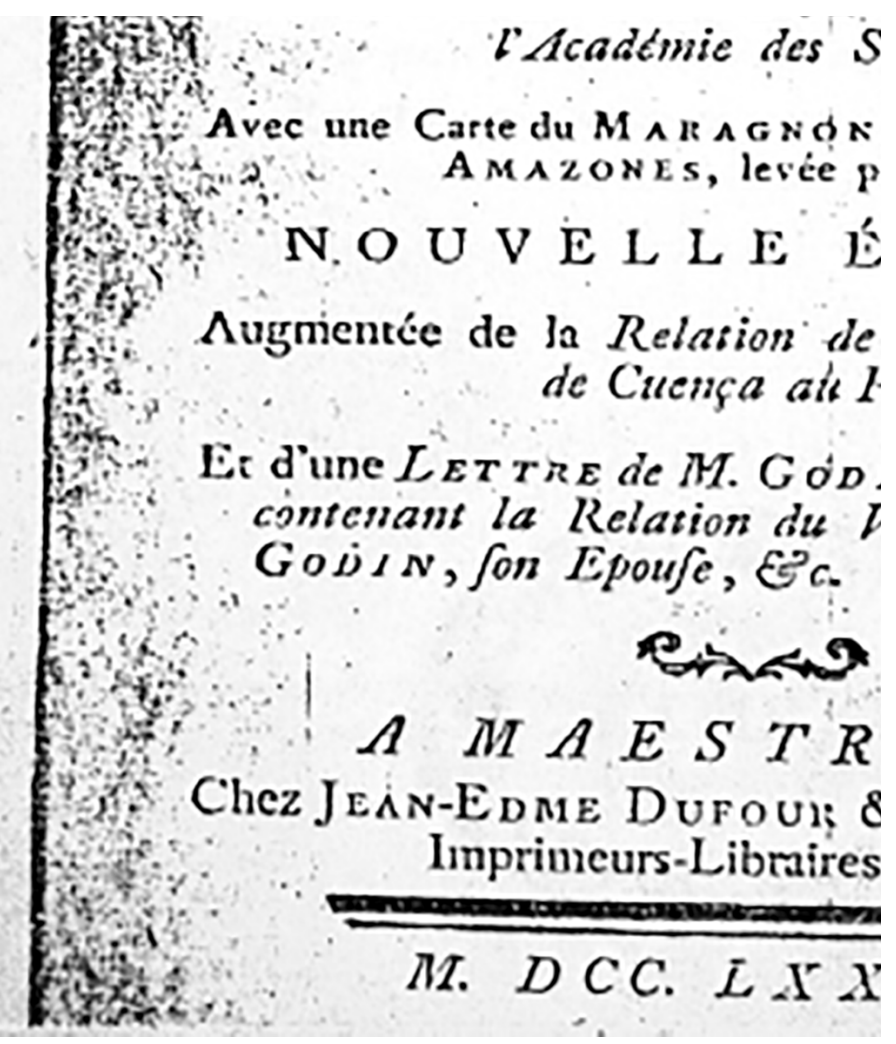




\section{Corpus del estudio}

\section{Versión francesa ${ }^{8}$}

\begin{tabular}{|c|c|c|}
\hline 1 & La même route que j'ai suivie & a. Suivre la route \\
\hline 2 & Nous vous prions de faire ag réer nos respects & a. (Faire) agréer les respects \\
\hline 3 & Qu'il m'était indispensable de mettre ordre & $\begin{array}{l}\text { a. Mettreordre (à) } \\
\text { à des affaires de famille }\end{array}$ \\
\hline 4 & $\begin{array}{l}\text { Que j'aie entrerpris si lestement un voyage de } \\
\text { quinze cents lieues, uniquement pour en } \\
\text { préparer un autre }\end{array}$ & $\begin{array}{l}\text { a. Entreprendre un voyage } \\
\text { b. Préparer un voyage }\end{array}$ \\
\hline 5 & $\begin{array}{l}\text { M. le Comte d'Hérouville avait la confiance } \\
\text { de M. le Duc }\end{array}$ & a. Avoir la confiance (de) \\
\hline 6 & (IIs) me donnassent des recommandations & a. Donner des recommandations \\
\hline 7 & $\begin{array}{l}\text { Que je chargerais de mes lettres et de tenir } \\
\text { ma place pour soignermafamille }\end{array}$ & a. Tenir la place \\
\hline 8 & Que vous descendîtes la rivière & a. Descendre la rivière (le fleuve, etc) \\
\hline 9 & Suivant les ordres qu'il avait reçus d'y attendre. & $\begin{array}{l}\text { a.Suivre les ordres. } \\
\text { b.Recevoir les orders }\end{array}$ \\
\hline 10 & Pour m'en procurer le débit & a. Procurer le débit \\
\hline 11 & Mais quelques diligences qu'on pût faire & a. Faire (des) diligences \\
\hline 12 & Surmonte les obstacles & a. Surmonter les obstacles \\
\hline 13 & $\begin{array}{l}\text { Le bruit de l'armement Portugais s'était } \\
\text { entendu jusqu' à Guayaquil }\end{array}$ & a. Entendre le bruit (le bruit est entendu) fig. \\
\hline 14 & Lui promettant qu'il veillerait sur sa santé & a. Veiller sur la santé (de qn) \\
\hline 15 & Mais ces difficultés furent bientôt levées & a. Lever les difficultés \\
\hline
\end{tabular}

8 En la versión francesa se encontraron 363 locuciones. Sin embargo, por razones de espacio, presentamos en este cuadro solo una selección de 15 . 


\section{Versión española9}

\begin{tabular}{|c|c|c|}
\hline 1 & $\begin{array}{l}\text { Me pedís un relato del viaje que hizo mi esposa } \\
\text { por el río de las Amazonas, siguiendo el mismo } \\
\text { itinerario que vos recorristeis antes. }\end{array}$ & $\begin{array}{ll}\text { b. } & \text { Hacer el viaje. } \\
\text { c. } & \text { Hacer el viaje por río. } \\
\text { d. } & \text { Seguir el itinerario }\end{array}$ \\
\hline 2 & $\begin{array}{l}\text { Que Su Majestad tuvo a bien que los señores (...) } \\
\text { me recomendasen a las autoridades }\end{array}$ & $\begin{array}{ll}\text { a. } & \text { Tener a bien } \\
\text { b. } & \text { Recomendar a las autoridades }\end{array}$ \\
\hline 3 & Le rogué que se pusiera en camino & Ponerse en camino \\
\hline 4 & Para que me gestionase su venta & Gestionar (una) venta \\
\hline 5 & Mme. Godin se decidió a ponerse en camino & Ponerse en camino \\
\hline 6 & Mi suegro, había tomado ya la delantera & Tomar la delantera \\
\hline 7 & Este camino no es transitable & Un camino transitable \\
\hline 8 & Lo cual les obligó a tomar tierra & Tomar tierra \\
\hline 9 & Atormentada de continuo por la ardiente sed & $\begin{array}{ll}\text { a. } & \text { La sed atormenta } \\
\text { b. } & \text { De continuo } \\
\text { c. } & \text { La sed ardiente }\end{array}$ \\
\hline 10 & Se precipita en un río & Precipitarse en un río \\
\hline 11 & Para pasar la noche & Pasar la noche \\
\hline 12 & Yque aún conserva preciosamente & Conservar preciosamente \\
\hline 13 & Qué razones me alegó & Alegar las razones \\
\hline 14 & Demasiado fundamento tenía mi esposa para ello & Tener fundamento para \\
\hline 15 & Remontó su barco & Remontar el barco \\
\hline
\end{tabular}

9 En la versión española se encontraron 513 locuciones. Sin embargo, por razones de espacio presentamos en este cuadro solo una selección de 15. 


\section{Resultados del análisis formal del corpus de investigación}

Entre las UF que constituyen las dos partes del corpus, hallamos expresiones de muy fácil traducción ya que en su mayoría se refieren a los hechos, sentimientos y puntos de vista generalizados y cotidianos.

\begin{tabular}{|l|l|}
\hline Los confusos rumores & Les bruits confus \\
\hline Tan doloroso es para mí su recuerdo & Tant le souvenir m'en est douloureux \\
\hline Tuve el honor de & J'eus l'honneur de \\
\hline Historia natural & Histoire naturelle \\
\hline Tener la bondad (de) & Avoir la bonté (de) \\
\hline Abusar de la paciencia & Abuser de la patience \\
\hline Descender el río & Descendre la rivière \\
\hline El mal ataca & Le mal attaque \\
\hline
\end{tabular}

En el texto francés se contabilizaron 363 locuciones de las cuales ochenta y cinco forman parte de lo que llamaremos los fraseologismos "entretejidos". Las ilustraciones de este término se pueden presentar, con igual o mayor grado de expresividad, en español como en francés. He aquí algunos ejemplos:

\section{Francés}

\begin{tabular}{|c|c|c|c|}
\hline 1. & "Les marques d'amitié que vous me donnez." & & $\begin{array}{l}\text { Les marques d'amitié } \\
\text { Donner les marques d'amitié }\end{array}$ \\
\hline 2. & $\begin{array}{l}\text { "il serait bon d'avoir sous les yeux la carte } \\
\text { que vous avez levée du cours d'Amazone" }\end{array}$ & $\begin{array}{l}\text { a. } \\
\text { b. }\end{array}$ & $\begin{array}{l}\text { Avoir sous les yeux } \\
\text { Lever la carte (de) }\end{array}$ \\
\hline 3. & $\begin{array}{l}\text { "Lui remit le paquet de lettres par une bévue } \\
\text { impardonnable, et qui a toute l'apparence } \\
\text { de la mauvaise volonté " }\end{array}$ & $\begin{array}{l}\text { a. } \\
\text { b. } \\
\text { c. }\end{array}$ & $\begin{array}{l}\text { Une bévue impardonnable } \\
\text { Avoir l'apparence de } \\
\text { La mauvaise volonté }\end{array}$ \\
\hline 4. & $\begin{array}{l}\text { Un bruit vague se répandit dans la Province } \\
\text { de Quito et parvint jusqu'à Madame Godin }\end{array}$ & $\begin{array}{l}\text { a. } \\
\text { b. } \\
\text { c. }\end{array}$ & $\begin{array}{l}\text { Un bruit vague } \\
\text { Un bruit se répand } \\
\text { Un bruit parvient }\end{array}$ \\
\hline 5. & Qui nous laissait la liberté de prendre la route & $\begin{array}{l}\text { a. } \\
\text { b. }\end{array}$ & $\begin{array}{l}\text { Laisser la liberté de } \\
\text { Prendre la route }\end{array}$ \\
\hline & $\begin{array}{l}\text { Et ayant perdu l'espérance à cet égard } \\
\text { ils firent un radeau }\end{array}$ & c. & $\begin{array}{l}\text { Perdre l'espérance } \\
\text { Àcet égard }\end{array}$ \\
\hline 7. & Tourmentée d'une soif ardente & $\begin{array}{l}\text { a. } \\
\text { b. }\end{array}$ & $\begin{array}{l}\text { Tourmenté de soif } \\
\text { La soif ardente }\end{array}$ \\
\hline 8. & $\begin{array}{l}\text { Mais un historien ne doit à son lecteur } \\
\text { que la simple vérité. Elle est attestée par les lettres } \\
\text { originales que j'ai entre les mains }\end{array}$ & $\begin{array}{l}\text { a. } \\
\text { b. }\end{array}$ & $\begin{array}{l}\text { La simple vérité } \\
\text { La vérité est attestée } \\
\text { Attester la vérité } \\
\text { Avoir entre les mains }\end{array}$ \\
\hline
\end{tabular}




\section{Ejemplos de fraseologismos "entretejidos" en español:}

\begin{tabular}{|c|c|c|c|}
\hline 1. & $\begin{array}{l}\text { Me pedís un relato del viaje que hizo mi esposa } \\
\text { or el río de las Amazonas, siguiendo el mismo } \\
\text { itinerario que vos recorristeis antes. }\end{array}$ & $\begin{array}{l}\text { a. } \\
\text { b. } \\
\text { c. } \\
\text { d. }\end{array}$ & $\begin{array}{l}\text { Hacer el viaje } \\
\text { Hacer el viaje por río } \\
\text { Seguir el itinerario } \\
\text { Recorrer el itinerario }\end{array}$ \\
\hline 2. & $\begin{array}{l}\text { Los confusos rumores que han llegado hasta vos } \\
\text { de los peligros a que se vio expuesta, y de los que } \\
\text { únicamente ella, de las ocho personas de la } \\
\text { expedición, escapó, aumenta vuestra curiosidad. }\end{array}$ & $\begin{array}{l}\text { a. } \\
\text { b. } \\
\text { c. } \\
\text { d. } \\
\text { e. }\end{array}$ & $\begin{array}{l}\text { Los confusos rumores } \\
\text { El rumor llega } \\
\text { Expornerse al peligro } \\
\text { Escapar del peligro } \\
\text { Aumentar la curiosidad }\end{array}$ \\
\hline 3. & $\begin{array}{l}\text { No se puede uno abrir paso más que hacha } \\
\text { en mano, perdiendo mucho tiempo }\end{array}$ & $\begin{array}{l}\text { a } \\
\text { b. } \\
\text { c. }\end{array}$ & $\begin{array}{l}\text { Abrir paso } \\
\text { Hacha en mano } \\
\text { Perder el tiempo }\end{array}$ \\
\hline 4. & $\begin{array}{l}\text { Tener a la vista el mapa que habéis trazado } \\
\text { del curso del Amazonas }\end{array}$ & $\begin{array}{l}\text { a. } \\
\text { b. } \\
\text { c. }\end{array}$ & $\begin{array}{l}\text { Tener a la vista } \\
\text { Trazar el mapa } \\
\text { El curso del río }\end{array}$ \\
\hline 5. & $\begin{array}{l}\text { Podría figurar en una esfera más elevada } \\
\text { que la de Pará }\end{array}$ & $\begin{array}{l}\text { a. } \\
\text { b. }\end{array}$ & $\begin{array}{l}\text { Figurar en una esfera } \\
\text { Una esfera elevada }\end{array}$ \\
\hline 6. & $\begin{array}{l}\text { Pero el título que invocáis de antiguo compañero } \\
\text { de viaje, título que me honra, la parte que tomáis } \\
\text { en cuanto nos interesa y las pruebas de amistad } \\
\text { que me dais... }\end{array}$ & $\begin{array}{l}\text { a. } \\
\text { b. } \\
\text { c. } \\
\text { d. } \\
\text { e. } \\
\text { f. }\end{array}$ & $\begin{array}{l}\text { Invocar el título } \\
\text { Antiguo compañero } \\
\text { Compañero de. vijae } \\
\text { Título honra } \\
\text { Tomar parte } \\
\text { Pruebas de amistad/dar prueba de amistad }\end{array}$ \\
\hline 7. & $\begin{array}{l}\text { A pesar de su malvada maniobra, se extendió } \\
\text { un vago rumor por la provincia de Quito, } \\
\text { y llegó a oídos de Mme. Godin, no solo de que } \\
\text { habían llegado las cartas para ella, las cuales } \\
\text { se remitieron a un Padre jesuita, sino que había } \\
\text { venido a las Misiones portuguesas más altas } \\
\text { en barco fletado por orden de Su Majestad } \\
\text { portuguesa para conducirla a Cayena }\end{array}$ & $\begin{array}{l}\text { a. } \\
\text { b. } \\
\text { c. } \\
\text { d. } \\
\text { e. } \\
\text { f. } \\
\text { g. } \\
\text { h. } \\
\text { i. }\end{array}$ & $\begin{array}{l}\text { A pesar de } \\
\text { Una maniobra malvada } \\
\text { Un rumor se extiende } \\
\text { Un rumor vago } \\
\text { Llegar a oídos } \\
\text { La }(s) \text { cartas llega }(n) \\
\text { Remitir la (s) carta ( } s \text { ) } \\
\text { Un barco fletado } \\
\text { Un barco conduce a alguien }\end{array}$ \\
\hline 8. & $\begin{array}{l}\text { Se había pagado por anticipado, } \\
\text { siguiendo la mala costumbre del país, } \\
\text { originada por la desconfianza, algunas veces } \\
\text { muy fundada }\end{array}$ & $\begin{array}{l}\text { a. } \\
\text { b. } \\
\text { c. } \\
\text { d. } \\
\text { e. } \\
\text { f. }\end{array}$ & $\begin{array}{l}\text { Pagar por anticipado } \\
\text { Por anticipado } \\
\text { La. mala costumbre } \\
\text { La desconfianza origina } \\
\text { La desconfianza fundada } \\
\text { Alguna (s) vez (ces) }\end{array}$ \\
\hline
\end{tabular}


En el texto español se encontraron 513 locuciones, 124 de las cuales son las llamadas "entretejidas". El porcentaje en ambos casos es casi igual. 23\% en francés y $24 \%$ en español, lo que nos permite hacer esta primera observación: las estructuras de ambos idiomas, en la misma medida, proporcionan la "materia prima" para este hecho lingüístico.

Ahora podemos pasar al primer punto que nos ocupa: la temática de los fraseologismos detectada en ambos textos.

En el texto francés se evidencian 18 temas principales alrededor de los cuales se agrupa la mayoría del material investigado; en el texto español ese número es de 22. Pero los que realmente nos interesan son los temas que se repiten en ambos idiomas. El análisis reduce estas cantidades a 13. Estos temas que aglomeran alrededor suyo en ambas versiones la mayor cantidad de fraseologismos son bastante previsibles, ya que van de acuerdo con el contenido de la carta de Louis Godin des Odonais:

$\begin{array}{ll}\text { 1. } & \text { Camino } \\ \text { 2. } & \text { Río } \\ \text { 3. } & \text { Burocracia } \\ \text { 4. } & \text { Viaje } \\ \text { 5. } & \text { Rumor } \\ \text { 6. } & \text { Distancia } \\ \text { 7. } & \text { Tiempo } \\ \text { 8. } & \text { Sentimientos } \\ \text { 9. } & \text { Tierra } \\ \text { 10 } & \text { Vida } \\ \text { 11. } & \text { Muerte } \\ \text { 12. } & \text { Auxilios } \\ \text { 13. } & \text { Órdenes }\end{array}$

Estudio de fraseología comparativa francés-español ...
En ambas lenguas, los trece temas indicados nos ofrecen la mayor concentración de fraseologismos. Aparte de estos se puede mencionar en el texto francés las siguientes palabras que agrupan una considerable cantidad de locuciones: "les yeux", "le témoin", "le souvenir", "la main", y las formas de "politesse" (cortesía). En la versión española además hay las siguientes palabras-núcleos que fomentan el mismo proceso: "sed", "privaciones", "itinerario", "cartas", "barco" (y todas las definiciones afines), "peligro", "seguridad", "asunto", "pie”.

El tercer punto, quizá uno de los más interesantes y que se devela únicamente en el proceso de registro de todas las locuciones en ambos idiomas, es la "paridad" o, dicho de otra manera, los casos cuando los dos textos se sirven de los fraseologismos para expresar el mismo pensamiento. Pues bien, en los textos existen 272 "parejas". De acuerdo con este número, en el texto francés se quedarían solo noventa y uno, y en el texto español 141 locuciones sin su respectivo paralelo. Esto queda claro con los siguientes ejemplos de paridad:

a) S'exposer au danger $<>$ exponerse al peligro Les marques d'amitie $<>$ las pruebas de amistad

Trouver bon $<>$ tener a bien

Remplir les vues <> colmar los deseos

Prendre le parti<> tomar el partido

Passer de main en main $<>$ pasar de mano en mano

Prendre les devants $<>$ tomar la delantera 
b) Cuando la locución existe solo en una de las dos lenguas:

\begin{tabular}{|l|l|}
\hline Avoir recours & Seguir el itinerario \\
\hline Faire des instances & Darse a la vela \\
\hline Avoir connaissance de & Recibir enhorabuena \\
\hline Donner lieu & Ala sazón \\
\hline Àla pointe du jour & Ponerse en camino \\
\hline Mettre aux fers & Hacerse cargo de \\
\hline
\end{tabular}

Aprovechando los ejemplos citados, se perfila claramente el grado de libertad de las locuciones en ambas lenguas. Los lazos entre las partes a veces son tan libres que solo concientizando la repetitividad podemos catalogar las locuciones como tales. Aún en estos casos, siempre (o casi siempre) podemos notar que uno de los componentes está más dependiente, más ligado al otro. Se puede decir que uno de ellos "llama" más al otro. Efectivamente, si consideramos algo tan sencillo a primera vista, como: "tomar el partido" ("prendre le parti") el verbo "tomar" - por sí solo- no nos obliga al empleo del segundo componente, pero en cambio, "el partido", "la decisión", casi inmediatamente, nos exige el verbo "tomar". Otros: 1) passer de main en main; 2) hacerse cargo de; 3) S'exposer au danger; 4) Tomar la delantera. Cabe indicar que este fenómeno se observa en la misma medida en ambos textos: francés y español.

El último acercamiento previsto al texto es la estructuración de los fraseologismos. Debido a que la idea principal es seguir, observar y registrar los puntos de convergencia de los dos textos, se tomarán en consideración únicamente las 272 “parejas”. Los resultados que arrojó el análisis fue el siguiente: de las 272 locuciones paralelas, tenemos 33 que con estructuras totalmente diferentes y 22 con estructuras parcialmente diferentes.

En consecuencia, las 217 locuciones, que constituyen casi el $80 \%$ de la totalidad de las locuciones paralelas en ambos idiomas, tienen sus estructuras totalmente idénticas.

Esto significa que las mismas formas y mecanismos presentes en ambos idiomas sirven, en un alto porcentaje del material investigado, para la expresión del mismo contenido. Es aquí, justamente en este impresionante porcentaje (80\%), donde encontramos la confirmación de que en ambos idiomas existen los procesos paralelos que llevan al pensamiento humano a evidenciarse en la misma forma. Ahora bien, surgen dos preguntas de fondo:

1) ¿Cuáles son los mecanismos generales de la creación de las locuciones?

2) ¿Qué condiciones deben cumplir esas unidades para tener su razón de ser?

Estos mecanismos del modo más general pueden resumirse de la siguiente manera:

a) El mecanismo de la asociación

b) El mecanismo de la metáfora

Muchas veces estos mecanismos se funden y se confunden en la misma locución. ¿A cuál de ellos podemos atribuir los siguientes ejemplos?

- El rumor llega

- Presentar los respetos

- Caber duda

- Caer enfermo 
- Abusar de la paciencia

- Colmar los deseos

- Llegar a oídos

- Echarse en brazos de la casualidad

- Volver sobre sus pasos

- Recibir con los brazos abiertos

- Llevar apellido

- S'exposer au danger

- Les marques d'amitié

- Jeter les yeux

- Remplir les vues

- Ajouter foi

- Mettre au hasard

- Prendre la route

- Rebrousser le chemin

- Perdre le temps

- Avoir entre les mains

- Mettre aux fers

- Donner un soupçon

Si queremos conservar intacta nuestra impresión al leer o escuchar estas expresiones, y si no queremos destruir su fuerza hurgando aún más de forma minuciosa en sus componentes, lo más viable quizá es únicamente polarizar las tendencias que se manifiestan en cada una de ellas hacia uno de los dos mecanismos mencionados.

La respuesta a la segunda pregunta: cuáles son esas "reglas del juego" a las que se someten las unidades fraseológicas para asegurar su supervivencia, es también muy generalizadora:

a) Estas unidades deben ser en el mayor grado posible extemporáneas, concernir los asuntos propios a todos los humanos, es decir, contener la mínima cantidad de los elementos específicos de una época concreta.

b) Tienen que destacarse por ciertos valores artísticos, poéticos, ser expresivos, o a veces fuertes y agudas. c) No pueden ser demasiado largas, complejas o rebuscadas en lo que se refiere a su sintaxis.

Todos los ejemplos citados a lo largo de este trabajo cumplen con esas condiciones.

\section{Reflexiones a modo de conclusión}

\section{Elementos de renovación en Fraseología}

Hay un aspecto interesante para ampliar las posibilidades del análisis de las palabras-llave o formas base de las UF; éste es el factor de la desautomatización que tiene su origen en los tratados de los formalistas rusos. Este proceso fue recobrado por A. Zuluaga como también por otros fraseólogos como Corpas Pastor, Ruiz Burillo y Zamora Muñoz. En el campo lingüístico se aplica para explicar las modificaciones tipo:

Darle a uno gato por liebre - darle a uno gato por euro

Dinero al contado - bofetones al contado

Cruzado de brazos - cruzado de estómago

El material que se investiga en este trabajo por su naturaleza no ofrece estas modificaciones que son propias de un texto con la intención de provocar el efecto de comicidad. También se debe tomar en cuenta que el baúl de los tesoros de las UF no está cerrado. Es una especie de baúl sin fondo que depende de la creatividad de los usuarios: del pueblo. Sobre este proceso permanente de creación, nos dicen dos investigadores de la Universidad de Granada: 
"De hecho todos los lenguajes humanos han crecido a partir de denominaciones elementales (partes del cuerpo, elementos próximos de la naturaleza, etc.) hasta denominaciones más abstractas e intelectuales. (...) Dentro de la constante lingüística $o$, si se prefiere, psicológica de los humanos de explicar o expresar 'cosas que no tienen nombre' por medio de otras que ya lo tienen, la Fraseología cumple un papel de esencial importancia. Las unidades fraseológicas de una lengua son el preservador natural de las creencias, tradiciones y símbolos de un pueblo y como tales, su estudio resulta tan interesante para el antropólogo y el historiador como para el lingüista. ${ }^{10}$ "

\section{Traducción}

Muy ligada a la problemática de las UF en la enseñanza está la de la traducción. Cabe destacar la faena sisífica de los traductores de la poesía. He aquí la reacción ante textos de extrema dificultad que desesperan e inclusive hacen retroceder. "Es imposible" dicen. ¿Por qué? Porque la lengua se resiste, no permite ser vulnerada en su máxima expresión: la Poesía. Obviamente que hay casos que permiten acercarse a su savia para transmitirla con algún acierto a otra lengua, pero no menos frecuente son aquellos que en realidad constituyen una especie de pacto de complicidad entre el traductor y su conciencia.
Aparentemente, nos estábamos alejando del tema de nuestro estudio, pero sólo aparentemente, ya que las UF son el arma principal de cada lengua para crear esas dificultades que inclusive fueron el tema de las Terceras Jornadas Internacionales de Fraseología Contrastiva en Alicante en noviembre de 2010. Este evento auspiciado por el Grupo de Investigación Frasitram (Fraseología y Traducción Multilingüe) trataba también el problema que representan las UF para los sistemas de traducción automática. Las carencias de las traducciones automáticas son muy fáciles de constatar revisando cualquier texto producto del uso de estos sistemas. $\mathrm{Y}$ a pesar de las protestas de Vladimir Nabokov, que abogaba por un traductor humano para los sentimientos de los poetas, nos encontramos ante un nuevo proyecto del buscador Google, el Poetic Machine TranslationPoética de Traducción Automática.

"Traducir es traicionar" es un decir que sigue siendo polémico desde los tiempos del patrono de los traductores, Saint Jérôme (Stridon, Dalmacia, 347- Belén 420). A partir de ahí se perfila y se acrecienta la importancia de la traducción (iy de los traductores!) en la historia intelectual del mundo. En este largo camino, la función comunicativa y los valores semánticos se oponen permanentemente a la parte estructural entre los textos de partida y los de llegada. Esta oposición es aplicable inclusive en el caso muy hipotético que el texto de partida no contenga ningún fraseologismo.

10 Juan de Dios Luque Durán y Francisco José Manjón Pozas, “Claves culturales del diseño de las lenguas: fundamentos de tipología fraseológica”, Universidad de Granada, España. Descargado de la red mundial el 28 de noviembre 2011. http://elies.rediris.es/elies16/Claves.html.. 


\section{Enseñanza}

Una de las metas de la actividad lingüística es indudablemente el dominio máximo en todos los niveles de la lengua. Esta competencia revela inmediatamente el grado de comprensión de las estructuras mentales y culturales de una lengua. Todos los elementos que entran en el ámbito fraseológico representan un peldaño más elevado en materia de la competencia léxica.

La Fraseología representa un verdadero reto en el camino de la enseñanza de los idiomas. La introducción paulatina de estos elementos requiere de un contexto de una mise en place y hasta de una mise en scène. La sistematización de este proceso hasta ahora no fue considerada como uno de los ejes de la metodología en la enseñanza de una lengua extranjera. Estas observaciones nos llevan directamente al tema de nuestra investigación: diferencias y similitudes entre dos (o varios) idiomas en el plano de sus riquezas fraseológicas.

La enseñanza nunca será completa sin el poder de discernir, sentir y aplicar las UF en la lengua a la cual se transmiten las UF del discurso o texto original. Las UF en la enseñanza de idiomas deberían ocupar un lugar que me gustaría definir como "natural" u "orgánico", es decir, no asignarles un capítulo, un párrafo o una sección especial separados del resto de los contenidos. La más pragmática competencia es el uso correcto de las UF que permite a los hablantes adecuar su propia producción a los diferentes contextos o registros discursivos. Así, en la práctica se justifica la aseveración de que con cada lengua aprendida nacemos una vez más, es decir, nos apropia- mos de los modelos mentales y culturales diferentes.

Las UF son los elementos más fáciles y rápidos de ser asimilados y proporcionan a los estudiantes una especial satisfacción por haber adquirido un conocimiento más íntimo de la lengua, y así superar las oraciones al modo de los manuales de enseñanza tipo "el lápiz está sobre la mesa", que nunca encontrarán en la vida real. Las UF permiten incrementar el grado de amplitud y precisión de los elementos que se utilizan formando parte de un trabajo integral de todo el proceso de la apropiación de la lengua.

\section{Defensa de la unidad de la lengua}

Hemos mencionado anteriormente varias posibilidades de clasificaciones y tipologías, así como varios puntos de partida, pero: ¿por qué el constante desmembramiento, si la Fraseología es una unión emblemática del espíritu del pueblo, de la lengua misma? Dentro de la Lingüística, la Fraseología simboliza el proceso de la unión. Si bien las innumerables y al parecer interminables clasificaciones tienen su razón de ser, como todo proceso analítico en cada ciencia, también es verdad que no se puede analizar infinitamente sin llegar a ninguna clase de síntesis indispensable en todo proceder gnoseológico.

Frente a esta posibilidad de clasificación o segmentación ad infinitum, proponemos considerar que hay aspectos, inclusive dentro de una ciencia tan estricta como la Lingüística, que merecerían quedar como inefables. Sin ir muy lejos, basta acordarse de que toda palabra escrita o pronunciada es palabra-clase. 
Palabra-clase quiere decir que es capaz de designar únicamente una clase de objetos, fenómenos, sentimientos, eventos, etc. (Claro está, excluyendo los nombres propios.) Tan sólo este hecho sería suficiente para legalizar el "pecado" de permitir que la lengua, la principal herramienta de la humanidad, conserve en parte su misterio, que no sea totalmente fragmentada y disecada. La Fraseología parece ser la última orilla dentro de la Lingüística que se resiste a ser conquistada, fenómeno que se manifiesta de manera especialmente evidente cuando abordamos el tema de la traducción.

¿Qué significa esto en la práctica? Los cientos de ejemplos, fruto del esfuerzo de los estudiantes a partir de la tarea de encontrar una UF correspondiente en otro idioma (en este caso, en francés), arrojan resultados muy sugerentes. Todos y cada uno de ellos, bien provistos de las más llamativas tecnologías, conseguían en aproximadamente 95\% de los casos, unas traducciones incluso gramaticalmente aceptables de las UF elegidas, pero totalmente despojadas de la función requerida. Por ejemplo, "buscar la quinta pata al gato" figuraba como algo absolutamente incomprensible para un francés: "chercher la cinquième patte à un chat", en vez de un expresivo "chercher midi à deux heures".

Este pequeño ejemplo es tan solo un botón de muestra para reafirmar hasta qué punto el sistema fraseológico está integrado en el sistema de la lengua. En sí, la separación de las UF de sus respectivos contextos ya es un proceso que, desde esta perspectiva, parece violentar la unidad de la lengua. Surgen las preguntas: ¿Qué tan natural es aquél proceso? ¿Hasta qué límite llega la necesidad de someterlo a los lineamientos del estructuralismo? ¿Cuáles serían los eventuales aportes que beneficiarían a la conservación y el desarrollo de las lenguas?

Sería contradictorio seguir aumentando las posibilidades de esta "disección” a la cual nos hemos opuesto. Más bien, queremos proponer una manera de delimitarla. Cada vez que un lingüistainvestigador inicia un trabajo de clasificación relacionado con los fraseologismos, hay dos preguntas ineludibles:

1. ¿Qué resultados prácticos se espera alcanzar al finalizar esa clasificación (o tipología)?

2. ¿Qué utilidad se transparenta a corto, mediano o largo plazo después de realizar esta acumulación de ejemplos repartida desde tal o cual punto de vista?

Mediante este trabajo queremos suscitar mayor interés hacia la importancia de esta rama de la Lingüística en nuestro medio, para que la Fraseología deje de ser la "Cenicienta" de la Lingüística ya que su valor real sigue creciendo con los siglos y nunca se acaba a medianoche. Como ya lo señalamos, la ciencia de la Fraseología es el resultado de la creatividad del Pueblo y Vox Populi - Vox Dei. 


\section{Bibliografía}

Babkin, A. M., La Fraseología rusa, su desarrollo y sus orígenes, Ed. Ciencia, Leningrado 1970.

Blancpain, Marc, Le plus long amour, Editorial Bernard Grasset, 1971, Paris.

Castillo Carballo, María Auxiliadora, "El concepto de unidad fraseológica", Revista de Lexicografía, Volumen IV, 1997. 1998, Grupo de lexicografía, Facultade de Filoloxía, Universidade da Coruña, La Coruña, 1998.

Charaudeau, Patrick, Grammaire du sens et de l'expressión, Hachette Éducation, Paris, 1992.

Daniel, Pilar, "Panorámica del argot español. Estudio introductorio" en Diccionario de argot español, Alianza Editorial, Madrid, 1986.

Gorelova, Oksana, "Dobletes etimológicos en Fraseología", Ogigia Revista electrónica de estudios hispánicos 8, 2010, http://www.ogigia.es/OGIGIA8_files/GORELOVA.pdf

Ignatova, Ekaterina, "Problemática de la Fraseología comparativa sobre las versiones polaca y rusa del Evangelio de San Lucas", Universidad Jagielloński de Copérnico, Facultad de Filología Polaca, Cracovia, noviembre 1972.

Iliná, Natalia, "La Fraseología española contemporánea: estado de la cuestión", Facultad de Lenguas Extranjeras adjunta a la Universidad Estatal Lomonosov de Moscú, Portal del Hispanismo http://hispanismo.cervantes.es/documentos/lina.pdf

La Condamine, Carlos María "Viaje a la América Meridional", [1745] Madrid, Espasa Calpe, 1942, Colección Austral, vol. 268.

La Condamine, Charles Marie Relation abrégée d'un voyage fait dans l'intérieur de l'Amérique méridionale, Maestricht, Imprimeurs-Libraires, associés, 1778

López Simó Mireia y Sierra Soriano Ascensión, "Fraseologismos pragmáticos reactivos: análisis contrastivo francés-español" enCuevas, Manuel Bruña et al La cultura del otro: español en Francia, francés en España. La culture de l'autre: espagnol en France, français en Espagne, APFUE

SHF Departamento de Filología Francesa de la Universidad de Sevilla, Sevilla, 2006.

Luque Durán, Juan de Dios y Manjón Pozas, Francisco José, "Claves culturales del diseño de las lenguas: fundamentos de tipología fraseológica", Universidad de Granada, España. http://elies.rediris.es/elies16/Claves.html.

Maldonado, Felipe C.R., "Estudio introductorio", Refranero clásico español, Ed. Taurus S.A., Madrid, 1985.

Martin, Jaime, "Estudio preliminar" en Diccionario de expresiones malsonantes del español. Léxico descriptivo, Ediciones ISTMO, Madrid, 1979.

Martinet, André, La linguistique synchronique, Presses Universitaires de France, Paris, 1974.

Martínez López, Juan, "La graduación en el proceso de aprendizaje de las expresiones fijas" en

Actas del I Congreso Internacional de Lengua, Literatura y Cultura Española: la Didáctica de la enseñanza para extranjeros, 2007.

Mena Martínez, Florentina, "En torno al concepto de desautomatización fraseológica: aspectos básicos", Revista Electrónica de Estudios Filológicos, Universidad de Murcia, www.um.es/tonosdigital/znum5/estudios/H-Edesautomatizacion.htm.

Molotkov, A.J., "Los fraseologismos del idioma ruso y los parámetros de su descripción lexicográfica. Estudio introductorio", Diccionario fraseológico del idioma ruso, Editorial Enciclopedia Soviética, Moscú, 1968.

Peramos Soler, Natividad y Batista Rodríguez, José Juan, "Unidades fraseológicas y variación", Ogigia Revista electrónica de estudios hispánicos 3, 2008, http://www.ogigia.es/OGIGIA3_files/OGIGIA3_PERAMOS_Y_BATISTA.pdf 
Ruiz Gurillo, Leonor, "Un enfoque didáctico de la Fraseología española para extranjeros" en Coperías, M.J., Sanmartín, J. (coord.) Quaderns de Filologia, Universitat de València, 1999.

Sciutto, Virgina Unidades fraseológicas: un análisis contrastivo de los somatismos del españól de Argentina y del italiano,Università di Napoli "L'Orientale'.

http:// cvc.cervantes.es/literatura/aispi/pdf/22/II_31.pdf

Sevilla, Julia, "Divergencias en la traducción de expresiones idiomáticas y refranes (francés-español", Electronic Journal of International Proverb Studies, volumen 5, noviembre 1999. http://www.deproverbio.com/display.php?a=3\&r=90

Sevilla, Julia, Arroyo, Álvaro, "La noción de 'expresión idiomática' en francés y en español", Revista de Filología Francesa, vol. 4, Editorial Complutense, Madrid, 1993.

Skorupka Stanislav, Diccionario fraseológico del idioma polaco, "Estudio introductorio", Editorial Ciencia Universal, Varsovia, 1967

Sopena, Ramón, "Prólogo", Iter Sopena de refranes y frases populares, Editorial Ramón Sopena S.A., Barcelona, 1984.

Šanski, N.M., Fraseología del idioma ruso contemporáneo, Escuela Superior Moscú, 1969.

Tercedor Sánchez, Maribel "La Fraseología en el lenguaje biomédico: análisis desde las necesidades del traductor", tesis doctoral, Departamento de Traducción e Interpretación, Universidad de Granada. http://148.216.10.84/freseologia/iii-metodo.htm.

Torrent-Lenzen, Aina, "Fraseología y comunicación de emociones", XV Congreso Internacional de Asociación de Lingüística y Filología de América Latina, Montevideo, agosto, 2008, Uruguay.

Tristan, Florence, Le procès des Étoiles, Editions Seghers, Paris 1979

Velasco Mackenzie, Jorge En nombre de un amor imaginario, Editorial El Conejo, Quito, Ecuador, 1996

Zulugaga, Alberto "Los 'enlaces frecuentes' de María Moliner. Observaciones sobre las Ilamadas colocaciones.", PhiNPhilologieimNetz, web.fu-berlin.de/phin/ 